\title{
Do the Rich Save More? A New View Based on Intergenerational Transfers
}

\author{
C. Simon Fan*
}

\begin{abstract}
Do richer people have higher saving rates? The short-run and long-run consumption functions have different answers to this question, which results in the "consumption puzzle" that was a focus of macroeconomic research in the 1950s and 1960s. In a recent empirical contribution, Dynan, Skinner, and Zeldes (2004) revive this old question and make this "consumption puzzle" more intriguing, by showing that the average propensity to consume decreases not only with current income but also with lifetime income. This paper provides a model that helps resolve this puzzle from an intergenerational perspective.
\end{abstract}

JEL Classification: E12, E21, D11

\section{Introduction}

Modern macroeconomic research on consumption/saving starts with Keynes (1936), who puts forward his well-known consumption function. An important implication of the Keynesian consumption function is that saving rate increases with income. However, although this predication is consistent with cross-sectional evidence, it is not consistent with time-series evidence. For example, in a seminal contribution, Kuznets (1946) discovered that the saving rate in the United States was remarkably stable from 1869 to 1938 even though people's incomes increased significantly during this period. ${ }^{1}$ Thus, the long-run consumption function implies that saving rate is constant with economic development. This important "consumption puzzle" motivated the celebrated contributions of the life-cycle hypothesis by Modigliani and Brumberg (1954) and the permanent-income hypothesis by Friedman (1957). In fact, the analysis and explanation for this "consumption puzzle" remains to be a fundamental issue in the teaching of modern macroeconomics. ${ }^{2}$

Despite an outpouring of early research on the "consumption puzzle" in the 1950s and 1960s, little work has been done since then, although this puzzle was not completely resolved either empirically or theoretically. Recently, an empirical contribution by Dynan, Skinner, and Zeldes (2004) significantly fills this gap and revives the old question of whether richer people save a larger fraction of their income. Using several large data sets, they find a strong positive relation between saving rates and lifetime income. This important empirical finding makes the

* Department of Economics, Lingnan University, Tuen Mun, Hong Kong; E-mail fansimon@ln.edu.hk; corresponding author.

I am grateful to two anonymous referees for their insightful and constructive comments and suggestions, which improved the paper significantly. Any remaining errors are my own.

Received August 2004; accepted January 2006.

${ }^{1}$ Many later studies also confirmed Kuznets' finding based on more recent and larger data sets (see the survey by Modigliani 1986).

${ }^{2}$ It is illustrated in several key texts, such as Dornbusch and Fischer (1994), Gordon (2003), and Mankiw (2003). 
old "consumption puzzle" more intriguing because it shows that the average propensity to consume decreases not only with current income, but also with lifetime income. Also, this puzzle can be further illustrated by the international comparison of saving rates: if richer people have higher saving rates, why has the United States, the wealthiest nation in the world, not had a higher saving rate than many poorer countries?

The current paper attempts to help resolve this puzzle. It extends the related literature by examining individuals' intertemporal choices with the explicit consideration of intergenerational altruism. This extension is empirically important because intergenerational transfers account for an important part of aggregate saving. Indeed, as demonstrated by Barro (1974) and Becker (1988), understanding intergenerational links is often crucial in the study of consumption, saving, and other macroeconomic issues.

My model implies that individuals are more concerned about their offspring's future wealth when they expect that the offspring's own endowment in the future is relatively low. The analysis shows that bequests from parents to children decrease with children's future mean income and increase with parental income. Thus, the model has the following implications. First, at a given point in time, richer people have higher saving rates because they are concerned that their children are likely to receive lower incomes than theirs. In other words, a household with higher lifetime income saves more in order to leave more bequests to its offspring, who are likely to be worse off. Second, over time, when an economy experiences economic growth and the mean income of the economy rises, individuals will reduce their bequests because their offspring are expected to be equally well off due to the economic growth. Consequently, the saving rate can be approximately constant over time if the impact of the increase in parents' lifetime income and the increase in their offspring's future mean income on parental consumption cancel out each other. Thus, this model helps explain the "consumption puzzle" and reconcile the short-run and long-run consumption functions. ${ }^{3}$

In what follows, section 2 provides a literature review. Section 3 examines the consumption functions in both the long and short run, and provides an explanation for the "consumption puzzle." Section 4 provides an extension of the basic model by examining the relation between the uncertainty of children's future earnings and parental consumption and bequests. Section 5 offers the concluding remarks.

\section{Literature Review}

\section{The Consumption Functions and the "Consumption Puzzle"}

The Keynesian consumption function can be written as $C=a+b Y$, where $C$ denotes consumption, $Y$ denotes disposable income, $a$ and $b$ are both positive coefficients, and $0<b<$ 1. The Keynesian consumption function, as simple as it is, has become a cornerstone in shortrun macroeconomics, such as the $I S$ - $L M$ model.

\footnotetext{
${ }^{3}$ Simply, this paper suggests that the "consumption puzzle" can be explained by considering individuals' incentive(s) to smooth consumption across generations of a dynasty.
} 
From this consumption function, the saving rate can be derived as

$$
s \equiv \frac{Y-C}{Y}=-\frac{a}{Y}+(1-b) .
$$

Clearly, the above equation implies that the saving rate increases with income $Y$. This predication is consistent with cross-sectional evidence. Moreover, in a recent empirical contribution, Dynan, Skinner, and Zeldes (2004) find that saving rates are positively correlated not only with current income but also with lifetime income.

However, as discussed in the introduction, the saving rate often remains remarkably stable over time despite substantial economic development. Thus, the long-run consumption function is defined in textbooks of macroeconomics (e.g., Mankiw 2003) as $C=\bar{c} Y$, where $\bar{c}$ is a positive constant. Indeed, the above long-run consumption function is consistent with a key assumption of the Solow growth model - that the saving rate of an economy is constant with economic development (Solow 1956).

The treatments of the "consumption puzzle" in modern textbooks of macroeconomics are the applications of the life-cycle hypothesis and the permanent-income hypothesis. For example, based on Modigliani's Nobel Prize speech, Mankiw (2003) describes it as follows: an individual lives for $T$ years and works for $R$ years. The individual has an annual salary $(Y)$ if he works and an initial wealth $(W)$. Assuming a perfect consumption-smoothing motive, the individual's annual consumption is

$$
C=\frac{W+R Y}{T}=\frac{W}{T}+\frac{R}{T} Y .
$$

It implies

$$
\frac{C}{Y}=\frac{W}{T Y}+\frac{R}{T}
$$

Then, the explanation proceeds as follows. In the short run, $W$ is constant and hence the consumption function is like the Keynesian consumption function; in the long run, $W$ increases with $Y$ in the same proportion and hence the saving (consumption) rate is constant over time.

However, natural questions arise. Where does the initial wealth come from? Why does the initial wealth increase with income? In another influential textbook, Dornbusch and Fischer (1994, p. 303; footnote 8) suggest that the initial wealth comes from bequests. In the same footnote, they also add: "In the fully developed life-cycle model, the individual, in calculating lifetime consumption, has also to take account of any bequests he or she may want to leave." Thus, more theoretical analyses that explicitly incorporate individuals' bequest motives are needed to reconcile the short-run and long-run consumption functions.

The permanent-income hypothesis of Friedman (1957) also provides an explanation for the "consumption puzzle." It argues that an individual's consumption is determined by the individual's current and previous incomes. On one hand, if the income in the previous period does not change (in the short run), an individual with higher current income will save more. On the other hand, if an economy experiences economic growth so that individuals recognize that their income in the previous period keeps increasing, their consumption will also increase over time. ${ }^{4}$ The current model provides an extension of the application of the permanent-income

\footnotetext{
${ }^{4}$ See, for example, Dornbusch and Fischer (1994) and Gordon (2003) for detailed explanations.
} 
hypothesis in explaining the "consumption puzzle," by regarding offspring's mean income as a permanent income (of a dynasty) from an intergenerational perspective. As the permanentincome hypothesis emphasizes that people experience random and temporary changes in their incomes, this extension is particularly interesting. It is because the randomness of an offspring's future income is usually much greater than the randomness of the individual's own income; for example, due to the uncertainty of the offspring's abilities and market luck. The current model investigates the effects of the changes of offspring's mean income on an individual's consumption/saving behaviors. This extension is especially useful in explaining the new empirical finding of Dynan, Skinner, and Zeldes (2004), that there is a strong positive relation between saving rates and lifetime income.

\section{Evidence on Intergenerational Transfers and Intergenerational Mobility}

The substantial empirical research in the past few decades reveals that intergenerational transfers are an important part of aggregate saving. ${ }^{5}$ Dynan, Skinner, and Zeldes (2002) point out three aspects to observe the importance of bequests in saving. First, bequests are often seen to be common and sizable. Second, bequests are often expected by the recipients. ${ }^{6}$ Third, most parents care about their children and value transferring resources to their children.

Also, there are a large number of empirical studies showing that there is a strong intergenerational correlation of economic status. For example, the intergenerational income elasticity between fathers and sons is estimated to be 0.4 or higher in the United States (Solon 1992), 0.23 in Canada (Corak and Heisz 1999), and 0.57 in Britain (Dearden, Machin, and Reed 1997). ${ }^{7}$ As shown empirically and theoretically by Bevan (1979), Behrman, Pollak, and Taubman (1989), Davies and Kuhn (1991), Galor and Zeira (1993), Mulligan (1999), and Restuccia and Urrutia (2004), among others, the difference in intergenerational transfers among rich and poor families is an important source of persistent income inequality, particularly when households face borrowing constraints.

Moreover, there is much evidence demonstrating that liquidity constraints affect a substantial proportion of U.S. consumers, particularly young individuals (Zeldes 1989; Cox 1990; Hubbard, Skinner, and Zeldes 1995). In this case, parents' transfers can substantially alleviate children's liquidity constraints and hence increase children's welfare. Indeed, Cox (1990) shows that intergenerational transfers are often allocated to liquidity-constrained consumers. Therefore, intergenerational transfers are an important source of intergenerational inequality, which suggests that parents have strong bequest motives if they are concerned about their children's welfare.

\section{The Model}

Consider an economy that is populated by a large number of families. Every family has one parent and one child. A parent's wealth is denoted by $Y_{t}$, which is a parameter in the model

\footnotetext{
${ }^{5}$ For example, see the surveys by Kotlikoff (1988), Gale and Scholz (1994), and Mulligan (1997).

${ }^{6}$ Weil (1994), for example, provides such an empirical study by comparing the savings of the elderly in micro and macro data.

${ }^{7}$ See Solon (2002) for the survey of empirical studies in many other countries.
} 
and may differ across families. The current model is based on the altruism model of Becker and Tomes (1979), who assume that parents obtain utility not only from their own consumption, but also from the "quality" of their children. Specifically, Becker and Tomes measure a child's "quality" by the child's total future wealth, and assume that an individual obtains utility from his or her material consumption, $C_{t}$, and the child's total future wealth, $Y_{t+1}$. Since a child's future income is uncertain, $Y_{t+1}$ is a random variable when the parent makes decisions on consumption and bequests. A parent's utility function is defined as

$$
u\left(C_{t}\right)+E v\left(Y_{t+1}\right)
$$

where $E$ stands for the expectation operator. We assume that

$$
u^{\prime}\left(C_{t}\right)>0, u^{\prime \prime}\left(C_{t}\right)<0, v^{\prime}\left(Y_{t+1}\right)>0, v^{\prime \prime}\left(Y_{t+1}\right)<0 .
$$

We denote a parent's bequests to his or her child as $B_{t}$. Then we have

$$
C_{t}+B_{t}=Y_{t}
$$

and

$$
w+(1+r) B_{t}=Y_{t+1},
$$

where $r$ is the interest rate and $w$ is the child's future endowment. Assume that $r$ is a constant and $w$ is a random variable; and that $w \sim(0, \infty)$ and $w \equiv \mu x$, where $\mu$ is a positive parameter. Note that $\mu$ is a key parameter of the model. Clearly, the greater $\mu$ is, the greater the child's expected future income. The density function of $x$ is denoted by $f()$. Based on the above description, (1) can be rewritten as

$$
u\left(Y_{t}-B_{t}\right)+\int_{0}^{\infty} v\left[(1+r) B_{t}+\mu x\right] f(x) d x .
$$

The optimal solutions are assumed to be interior, which is the focus of this paper. ${ }^{8}$ Taking the derivation of (5) with respect to $B_{t}$, the first-order condition is

$$
-u^{\prime}\left(Y_{t}-B_{t}\right)+(1+r) \int_{0}^{\infty} v^{\prime}\left[(1+r) B_{t}+\mu x\right] f(x) d x=0 .
$$

From (6), we have the following proposition.

Proposition 1. Under the above stated assumptions,

(i) $0<\frac{\partial C_{t}}{\partial Y_{t}}<1$,

(ii) $\frac{\partial C_{t}}{\partial \mu}>0$

Proof. (i) Totally differentiating (6) with respect to $B_{t}$ and $Y_{t}$, and then rearranging, we get

\footnotetext{
${ }^{8}$ Note that under some circumstances, children's future earnings may be very low or they may be subject to liquidity constraints. In this case, parents' marginal utility from bequests will be very high. Therefore, it is reasonable to assume that if bequests approach zero, the marginal utility from bequests will be very large, which rules out the corner solution of intergenerational transfers for most parents.
} 


$$
\frac{d B_{t}}{d Y_{t}}=\frac{u^{\prime \prime}}{u^{\prime \prime}+(1+r)^{2} \int_{0}^{\infty} v^{\prime \prime} f(x) d x} .
$$

From (2), we know $u^{\prime \prime}<0$ and $\int_{0}^{\infty} v^{\prime \prime} f(w) d w<0$. Thus, both the numerator and the denominator of the right side of (7) are negative; the absolute value of the numerator of the right side of (7) is less than that of the denominator. Therefore, we have

$$
0<\frac{d B_{t}}{d Y_{t}}<1
$$

Noting $C_{t}=Y_{t}-B_{t}$, we have

$$
\frac{d C_{t}}{d Y_{t}}=1-\frac{d B_{t}}{d Y_{t}}
$$

Thus we have

$$
0<\frac{\partial C_{t}}{\partial Y_{t}}<1
$$

(ii) Totally differentiating (6) with respect to $B_{t}$ and $\mu$, and rearranging, we have

$$
\frac{d B_{t}}{d \mu}=-\frac{(1+r) \int_{0}^{\infty} x v^{\prime \prime} f(x) d x}{u^{\prime \prime}+(1+r)^{2} \int_{0}^{\infty} v^{\prime \prime} f(x) d x}<0 .
$$

Noting $C_{t}=Y_{t}-B_{t}$, we have

$$
\frac{d C_{t}}{d \mu}=-\frac{d B_{t}}{d \mu} .
$$

Thus we have

$$
\frac{\partial C_{t}}{\partial \mu}>0
$$

Since an individual's consumption is determined by personal income and the offspring's expected future income, as a first-order approximation, we can write an individual's "consumption function" as

$$
C_{t}=\eta Y_{t}+\pi \mu,
$$

where $\eta=\frac{\partial C_{t}}{\partial Y_{t}}, \pi=\frac{\partial C_{t}}{\partial \mu}$. By Proposition $1, \pi>0$, and the "marginal propensity to consume," $\eta$ is between 0 and 1. In the following, we can show that the consumption function (9) provides an explanation for the empirical observation about the "average propensity to consume" (i.e., $\frac{C_{t}}{Y_{t}}$ ) in the short and long run.

An important component of Keynes' general theory (1936) is the Keynesian consumption function, which implies that the average propensity to consume decreases with income. However, as discussed in the introduction, empirical evidence shows that although this implication is consistent with cross-sectional evidence, it is rejected by time-series evidence. This 
paper helps to explain these seemingly contradictory findings. From (9), the "average propensity to consume" can be expressed as

$$
\frac{C_{t}}{Y_{t}}=\eta+\pi \frac{\mu}{Y_{t}}
$$

In the short run, children's future mean income, $\mu$, is constant, which implies that the "average propensity to consume," $\frac{C_{t}}{Y_{t}}$, decreases with income $Y_{t}$. This implication is consistent with the empirical finding by Dynan, Skinner, and Zeldes (2004), that there is a negative relation between consumption rates and lifetime income. In the long run, $\mu$ and the mean of $Y_{t}$ increase in the same proportion, which implies that over time the "average propensity to consume" in aggregate remains approximately constant as $Y_{t}$ (and $\mu$ ) rises. Thus, from an intergenerational perspective, Proposition 1 presents a new explanation for the "consumption puzzle" and helps provide reconciliation for the short-run and long-run consumption functions.

Indeed, the essential idea of this paper is similar to that of an early empirical study by Brady and Friedman (1947), which Modigliani (1986, p. 298) described as a "path-breaking contribution" in his Nobel Prize speech. Brady and Friedman (1947) offer the first intuitive reconciliation for the short-run and long-run consumption functions with supporting evidence. They show that at a given point in time, households with higher incomes save a larger fraction of their income, which confirms Keynes' conjecture. However, over time the consumption function shifted up as mean income increased. Consequently, the saving rate can be approximately constant in the long run. The current paper provides a further explanation of the empirical finding of Brady and Friedman (1947) from an intergenerational perspective.

\section{An Extension: Intergenerational Uncertainty and the Consumption Function}

In this section, I provide an extension of the basic model by analyzing the uncertainty of children's future incomes as another possible determinant of the consumption function. For example, Becker and Tomes (1979) argue that since "market luck" and "endowment luck" differ across individuals, a child's future earnings can be very uncertain. Thus, this extension explores an issue that is empirically significant.

To provide a benchmark of comparison, we first consider the situation in which there is no uncertainty as for children's future income. In this case, we denote a child's future income by $\bar{w},{ }^{9}$ which is a positive constant. Then we can write a parent's utility function as follows:

$$
u\left(C_{t}\right)+E v\left(Y_{t+1}\right)=u\left(Y_{t}-B_{t}\right)+v\left[(1+r) B_{t}+\bar{w}\right] .
$$

The first-order condition of (11) is

$$
-u^{\prime}\left(Y_{t}-B_{t}\right)+(1+r) v^{\prime}\left[(1+r) B_{t}+\bar{w}\right]=0 .
$$

\footnotetext{
${ }^{9}$ In relation to the notations in the last section, $\bar{w}$ may be regarded as being equal to $\mu \mathrm{E} x$.
} 
We denote the solution to (12) by $B^{C}$.

Next, we add uncertainty into the analysis by assuming that a child's future income is $\bar{w}+\tilde{z}$, where $\tilde{z}$ is a random variable with mean zero. ${ }^{10}$ Namely,

$$
E(\tilde{z})=0 .
$$

In this case, we can write a parent's utility function as follows:

$$
u\left(C_{t}\right)+E v\left(Y_{t+1}\right)=u\left(Y_{t}-B_{t}\right)+E v\left[(1+r) B_{t}+\bar{w}+\tilde{z}\right]
$$

The first-order condition of (14) is

$$
-u^{\prime}\left(Y_{t}-B_{t}\right)+(1+r) E v^{\prime}\left[(1+r) B_{t}+\bar{w}+\tilde{z}\right]=0 .
$$

We denote the solution to (15) by $B^{U}$. Suppose that the distribution of $\tilde{z}$ does not degenerate into a single point zero. Then we have the following lemma.

Lemma 1. Under the above stated assumptions, if $v^{\prime \prime \prime}>0$, then $B^{U}>B^{C}$.

Proof. We prove it by contradiction. Suppose that $B^{U} \leq B^{C}$. Then we have

$$
Y_{t}-B^{U} \geq Y_{t}-B^{C} \text {. }
$$

Recall that $u^{\prime \prime}<0$. Then (16) implies that

$$
u^{\prime}\left(Y_{t}-B^{U}\right) \leq u^{\prime}\left(Y_{t}-B^{C}\right) .
$$

Also, note that $v^{\prime \prime \prime}>0$ means that the function $v^{\prime}$ is convex, which implies

$$
\begin{aligned}
E v^{\prime}\left[(1+r) B_{t}+\bar{w}+\tilde{z}\right]>v^{\prime}\left\{E\left[(1+r) B_{t}+\bar{w}+\tilde{z}\right]\right\} & =v^{\prime}\left[(1+r) B_{t}+\bar{w}+E(\tilde{z})\right] \\
& =v^{\prime}\left[(1+r) B_{t}+\bar{w}\right]
\end{aligned}
$$

If $B^{U} \leq B^{C}$, then from (18) and $v^{\prime \prime}<0$ we have

$$
E v^{\prime}\left[(1+r) B^{U}+\bar{w}+\tilde{z}\right]>v^{\prime}\left[(1+r) B^{U}+\bar{w}\right] \geq v^{\prime}\left[(1+r) B^{C}+\bar{w}\right] .
$$

Since $B^{C}$ and $B^{U}$ are the solutions to (12) and (15), respectively, we have

$$
-u^{\prime}\left(Y_{t}-B^{C}\right)+(1+r) v^{\prime}\left[(1+r) B^{C}+\bar{w}\right]=0
$$

and

$$
-u^{\prime}\left(Y_{t}-B^{U}\right)+(1+r) E v^{\prime}\left[(1+r) B^{U}+\bar{w}+\tilde{z}\right]=0 .
$$

Also, from (17) and (19) we have

$$
\begin{aligned}
& -u^{\prime}\left(Y_{t}-B^{U}\right)+(1+r) E v^{\prime}\left[(1+r) B^{U}+\bar{w}+\tilde{z}\right] \\
> & -u^{\prime}\left(Y_{t}-B^{C}\right)+(1+r) v^{\prime}\left[(1+r) B^{C}+\bar{w}\right] .
\end{aligned}
$$

Then from (20) and (22) we get

$$
-u^{\prime}\left(Y_{t}-B^{U}\right)+(1+r) E v^{\prime}\left[(1+r) B^{U}+\bar{w}+\tilde{z}\right]>0 .
$$

\footnotetext{
${ }^{10}$ In relation to the notations in the last section, $\widetilde{z}$ may be regarded as being equal to $\mu x-\bar{w}$.
} 
Clearly, (23) is in contradiction with (21). Thus, we have proved this lemma.

Note that the assumption $v^{\prime \prime \prime}>0$ is commonly made in the existing literature about an individual's precautionary saving in response to the uncertainty of his or her own future income (e.g., Kimball 1990). Moreover, from the above analysis, it is easy to see that the greater $v^{\prime \prime \prime}$ is, the greater the difference between $B^{U}$ and $B^{C}$. Thus, under reasonable conditions, the uncertainty of children's future income can be an important source of intergenerational transfers.

Next, we try to examine the monotonic relationship between the uncertainty of children's future income and parents' consumption. In doing so, we first modify the expression of the density function of $x$ (in section 3 ) into $f(x, \delta)$, where $\delta$ denotes the standard error of $x$. Also, corresponding to the notations $B^{C}$ and $B^{U}$, we denote $C^{C}$ and $C^{U}$ as an individual's consumption when the offspring's future income is certain and uncertain, respectively. Then we have the following proposition.

Proposition 2. (i) Under the above stated assumptions, if $v^{\prime \prime \prime}>0$, then we have $C^{C}>C^{U}$. (ii) Under the above stated assumptions, $\frac{d C_{t}}{d \delta}<0$ if the following condition is satisfied:

$$
\int_{0}^{\infty} v^{\prime}\left[(1+r) B_{t}+\mu x\right] f_{2}(x, \delta) d x>0 .
$$

Proof. (i) Noting $C_{t}=Y_{t}-B_{t}$, the proof of Part (i) of Proposition 2 follows Lemma 1 directly. (ii) Replacing $f(x)$ with $f(x, \delta)$, we can rewrite the first-order condition (6) as

$$
-u^{\prime}\left(Y_{t}-B_{t}\right)+(1+r) \int_{0}^{\infty} v^{\prime}\left[(1+r) B_{t}+\mu x\right] f(x, \delta) d x=0 .
$$

Totally differentiating (25) with respect to $B_{t}$ and $\delta$, and rearranging, we get

$$
\frac{d B_{t}}{d \delta}=-\frac{(1+r) \int_{0}^{\infty} v^{\prime}\left[(1+r) B_{t}+\mu x\right] f_{2}(x, \delta) d x}{u^{\prime \prime}\left(Y_{t}-B_{t}\right)+(1+r)^{2} \int_{0}^{\infty} v^{\prime \prime}\left[(1+r) B_{t}+\mu x\right] f(x, \delta) d x} .
$$

Clearly, the denominator of the right side of (26) is negative. Thus, if (24) is satisfied, we will have $\frac{d B_{t}}{d \delta}>0$, which from $C_{t}=Y_{t}-B_{t}$ implies $\frac{d C_{t}}{d \delta}<0$.

Part (i) of this proposition indicates that individuals may consume more if there is no uncertainty in their children's future income. Part (ii) of Proposition 2 implies that under some additional conditions, an individual's marginal propensity to consume with respect to the marginal changes of the uncertainty of the offspring's future income is negative. Therefore, if the income distribution of an economy becomes more equal, people tend to consume more and leave fewer bequests to their children. ${ }^{11}$ In sum, Proposition 2 suggests that the change of the uncertainty of children's future income may affect the consumption function, and the estimation of the magnitude of this impact can be an interesting topic in future empirical research.

${ }^{11}$ The implication of this proposition appears to be consistent with some empirical observations. For example, Couch and Dunn (1997) estimate that the intergenerational income elasticity between fathers and sons is only 0.11 in Germany, where the uncertainty of children's future net earnings is relatively small due to substantial income redistribution through taxes and subsidies. Galor and Moav (2004) also emphasize the importance of income distribution for saving and bequests from a perspective different from that of the current paper. 


\section{Conclusion}

An important implication of the Keynesian consumption function is that saving rate increases with income. However, this predication is consistent only with cross-sectional evidence but not with time-series evidence. This "consumption puzzle," which motivated the Noble Prize-winning contributions of Modigliani and Brumberg (1954) and Friedman (1957), is clearly one of the most important empirical findings. More recently, a comprehensive empirical study by Dynan, Skinner, and Zeldes (2004) finds a strong positive relation between saving rates and lifetime income. This important finding makes the old "consumption puzzle" more intriguing, and calls for more theoretical analysis to explain why richer people have higher saving rates in cross-sectional data but there is no strong correlation between income and saving rate in time-series data or in international comparisons. The current paper attempts to help fill this gap. It extends the related existing literature by examining individuals' intertemporal choices from an intergenerational perspective.

The present model implies that an individual is more concerned about his or her offspring's future wealth when the individual expects that the offspring's own endowment in the future is relatively low. It shows that bequests from parents to children decrease with children's mean income and increases with parental income. Thus, at a given point in time, richer people have higher saving rates because they are concerned that their children are likely to receive lower incomes than theirs. In other words, a household with higher lifetime income saves more in order to leave more bequests to its offspring, who are likely to be worse off. However, over time, when an economy experiences economic growth and the mean income of the economy rises, individuals will reduce their bequests because their offspring are expected to be equally well off owing to the economic growth. Consequently, the saving rate can be approximately constant over time if the impacts of the increase in one's lifetime income and the increase in the offspring's future mean income on the individual's consumption cancel out each other. Thus, this model helps explain the "consumption puzzle" and reconcile the short-run and long-run consumption functions.

Furthermore, I provide an extension of the basic model by analyzing the uncertainty of children's future incomes as another possible determinant of the consumption function. The analysis indicates that individuals will consume more if there is no uncertainty in terms of their children's future income. Also, under some reasonable conditions, it shows that an individual's marginal propensity to consume with respect to the marginal changes of the uncertainty of the offspring's future income is negative. Therefore, as the income distribution of an economy becomes more equal, people may tend to consume more and leave fewer bequests to their children.

I have used the simplest model to highlight the essential idea of the paper. In future research, the model can be extended to examine more detailed interactions between parents and children in a framework in which parents obtain utility from the quantity and the quality of their offspring, and in which parents may be concerned about their offsprings' survival probability if the economy is poor. ${ }^{12}$ Also, the model may be extended further by incorporating the uncertainty facing parents themselves, such as uncertain lifetime and the possibility of illness, together with the uncertainty of children's future income in a unified framework.

\footnotetext{
${ }^{12}$ For example, see Galor and Weil (2000), Fan (2001, 2005), and Galor and Moav (2002).
} 


\section{References}

Barro, Robert J. 1974. Are government bonds net wealth? Journal of Political Economy 48:1095-118.

Becker, Gary. 1988. Family economics and macro behavior. American Economic Review 78:1-13.

Becker, Gary, and Nigel Tomes. 1979. An equilibrium theory of the distribution of income and intergenerational mobility. Journal of Political Economy 87:1153-89.

Behrman, Jere R., Robert A. Pollak, and Paul Taubman. 1989. Family resources, family size, and access to financing for college education. Journal of Political Economy 97:398-419.

Bevan, D. L. 1979. Inheritance and the distribution of wealth. Economica 46:381-402.

Brady, D. S., and R. D. Friedman. 1947. Savings and the income distribution. In NBER studies in income and wealth. Volume 10. New York: National Bureau of Economic Research, pp. 247-65.

Corak, Miles, and Andrew Heisz. 1999. The intergenerational earnings and income mobility of Canadian men: Evidence from longitudinal income tax data. Journal of Human Resources 34:504-33.

Couch, Kenneth A., and Thomas A. Dunn. 1997. Intergenerational correlations in labor market status: A comparison of the United States and Germany. Journal of Human Resources 32:210-32.

Cox, Donald. 1990. Intergenerational transfers and liquidity constraints. Quarterly Journal of Economics 105:187-217.

Davies, James B., and Peter J. Kuhn. 1991. A dynamic model of redistribution, inheritance, and inequality. Canadian Journal of Economics 24:324-44.

Dearden, Lorraine, Stephen Machin, and Howard Reed. 1997. Intergenerational mobility in Britain. Economic Journal 107:47-66.

Dornbusch, Rudiger, and Stanley Fischer. 1994. Macroeconomics. New York: McGraw-Hill.

Dynan, Karen E., Jonathan Skinner, and Stephen P. Zeldes. 2002. The importance of bequests and life-cycle saving in capital accumulation: A new answer. American Economic Review 92:274-8.

Dynan, Karen E., Jonathan Skinner, and Stephen P. Zeldes. 2004. Do the rich save more? Journal of Political Economy $112: 397-444$.

Fan, C. Simon. 2001. A model of intergenerational transfers. Economic Theory 17:399-418.

Fan, C. Simon. 2005. Survival of the gene, intergenerational transfers and precautionary saving. Journal of Development Economics 76:451-79.

Friedman, Milton. 1957. A theory of the consumption function. Princeton, NJ: Princeton University Press.

Gale, William G., and John Karl Scholz. 1994. Intergenerational transfers and the accumulation of wealth. Journal of Economic Perspectives 8:145-60.

Galor, Oded, and Omer Moav. 2002. Natural selection and the origin of economic growth. Quarterly Journal of Economics 117:1133-92.

Galor, Oded, and Omer Moav. 2004. From physical to human capital accumulation: Inequality and the process of development. Review of Economic Studies 71:1001-26.

Galor, Oded, and David N. Weil. 2000. Population, technology, and growth: From Malthusian stagnation to the demographic transition and beyond. American Economic Review 90:806-28.

Galor, Oded, and Joseph Zeira. 1993. Income distribution and macroeconomics. Review of Economic Studies 60:35-52.

Gordon, Robert J. 2003. Macroeconomics. Boston, MA: Addison-Wesley.

Hubbard, R. Glenn, Jonathan Skinner, and Stephen P. Zeldes. 1995. Precautionary saving and social insurance. Journal of Political Economy 103:360-99.

Keynes, John Maynard. 1936. General theory of employment, interest and money. New York: Harcourt Brace \& Company.

Kimball, Miles S. 1990. Precautionary saving in the small and in the large. Econometrica 58:53-73.

Kotlikoff, Laurence J. 1988. Intergenerational transfers and saving. Journal of Economic Perspectives 2:41-58.

Kuznets, Simon S. 1946. National income: A summary of findings. New York: Arno Press.

Mankiw, N. Gregory. 2003. Macroeconomics. New York: Worth Publishers.

Modigliani, Franco. 1986. Life cycle, individual thrift, and the wealth of nations. American Economic Review 76:297-313.

Modigliani, Franco, and Richard Brumberg. 1954. Utility analysis and the consumption function: an interpretation of cross-section data. In Post-Keynesian economics, edited by Kenneth K. Kurihara. New Brunswick, NJ: Rutgers University Press.

Mulligan, Casey B. 1997. Parental priorities and economic inequality. Chicago: University of Chicago Press.

Mulligan, Casey B. 1999. Galton versus the human capital approach to inheritance. Journal of Political Economy 107:S184-S224.

Restuccia, Diego, and Carlos Urrutia. 2004. Intergenerational persistence of earnings: The role of early and college education. American Economic Review 94:1354-78.

Solon, Gary. 1992. Intergenerational income mobility in the United States. American Economic Review 82:393-408.

Solon, Gary. 2002. Cross-country differences in intergenerational earnings mobility. Journal of Economic Perspectives 16:59-66. 
Solow, Robert M. 1956. A contribution to the theory of economic growth. Quarterly Journal of Economics 70:65-94. Weil, David N. 1994. The saving of the elderly in micro and macro data. Quarterly Journal of Economics 109:55-81.

Zeldes, Stephen P. 1989. Consumption and liquidity constraints: An empirical investigation. Journal of Political Economy 97:305-46. 